\section{To resuscitate or not?}

Sir,

Potter and colleagues suggest that elderly hospital patients should routinely be asked their opinions about cardiopulmonary resuscitation, ${ }^{1}$ but this is often unnecessary from an ethical viewpoint, ${ }^{2}$ and might even be unwelcome to patients. ${ }^{3,4}$

It may be appropriate to discuss cardiopulmonary resuscitation with patients where there is a reasonable chance that it will be successful, although many patients are excluded from resuscitation because the chances of survival are so poor that it is considered futile. Ethicists agree that doctors can legitimately make Do Not Resuscitate decisions in these patients without the need to obtain consent. ${ }^{2}$ We have calculated morbidity scores, which have been shown to predict failure to survive cardiopulmonary resuscitation, ${ }^{5}$ for all our acute elderly inpatients, and have found that $30 \%$ of them were predicted not to survive by two separate scores (unpublished data). Discussing cardiopulmonary resuscitation with these patients seems unnecessary, and possibly counterproductive.

Potter and colleagues state that they gave patients a layman's explanation of cardiopulmonary resuscitation, without trying to predict the outcome for individuals, and found that almost all patients wanted resuscitation for themselves. Their results are in contrast with those of Murphy and colleagues, ${ }^{6}$ who found that very few elderly patients wanted cardiopulmonary resuscitation after they had been given a detailed explanation of their chances of surviving. Information on outcome is important in any discussion about treatment, especially when, as in the case of cardiopulmonary resuscitation, the success rate is low. Perhaps Potter's patients were inadvertently led to believe that cardiopulmonary resuscitation was nearly always successful whereas, of course, it is usually unsuccessful.

Even when it is appropriate to involve patients in these decisions, some may not wish to participate, and others may misunderstand what is being discussed. The Vice-President of the Patients' Association has been quoted in the national press as saying that a policy of discussing cardiopulmonary resuscitation with all elderly patients might be cruel or intrusive. ${ }^{3}$ Heller and colleagues implemented such a policy, but found that a patient's relative took exception to the practice, and they were misrepresented by the local media as running a covert euthanasia policy. ${ }^{4}$ They suggest that others proceed with caution before embarking on such policies.

If ethical guidelines ${ }^{2}$ for making decisions not to resuscitate are followed then it is likely that only a minority of elderly patients will become involved in discussing cardiopulmonary resuscitation. Nearly half of Potter's patients (and $37 \%$ of ours, unpublished data) would be excluded because of cognitive impairment, and perhaps another third because of futility. We would expect that there would be others who would not wish to discuss the issue, would be too ill to discuss it, or in whom a senior clinician felt that discus-

\section{Learning points}

- many elderly patients may have Do Not Resuscitate decisions made on the basis of futility. Doctors do not need consent for these decisions

- if resuscitation is discussed with patients then they should be given realistic information about their chances of survival; this may affect their preferences

- patients may not want to discuss resuscitation, or may misunderstand what is being proposed

- many elderly patients will be unable to discuss resuscitation because of cognitive impairment

sion would be detrimental to their wellbeing. This is an acceptable ethical position. ${ }^{2}$

When discussions about cardiopulmonary resuscitation do take place, patients should be given realistic information about likely outcome, so as they can make a truely informed decision.

KEVIN STEWART Newham General Hospital, London E13 8RU, UK ADRIAN WAGG

Department of Geriatric Medicine, Northwick Park Hospital, Harrow, UK MARK KINIRONS

Department of Health Care of the Elderly, King's College Hospital, London, UK

1 Potter JM, Stewart D, Duncan G. Living wills: would sick people change their minds? Postgrad Med f 1994; 70: 818-20.

2 Doyal L, Wilsher D. Withholding cardiopulmonary resuscitation: proposals for formal monary resuscitation: proposals for
guidelines. BMJ 1993; 306: 1593-6.

3 Tomlin Z. A matter of life and death. Guardian 1994; 5 October.

4 Heller A, Potter J, Sturgess I, Owen A, McCormack $P$. Resuscitation and patients' views; questioning may be misunderstood by some patients. $B M \mathcal{F}$ 1994; 309: 408.

5 O'Keefe S, Ebell MH. Prediction of failure to survive following in-hospital cardiopulmonary resuscitation: comparison of two predictive scores. Resuscitation 1994; 28: 21-5.

6 Murphy DJ, Burrows D, Santilli S, et al. The influence of the probability of survival on patients' preferences regarding patients' preferences regarding cadiopulmonary

\section{Septic arthritis of the hip complicating pregnancy}

Sir,

Septic arthritis of the hip joint in adults is uncommon. Patients often have predisposing factors and there is often a primary source of infection. ${ }^{1}$ We have recently seen a patient with a group B streptococcal septic arthritis of the hip; it is rare to find this organism infecting a joint. The hip and sacroiliac joints seem to be particularly at risk from postnatal sepsis. Because of the variety of organisms and their differing antibiotic sensitivities a bacterial diagnosis should always be sought to ensure effective treatment.
A 43-year-old woman presented to our department three months following delivery of a healthy baby at full term. She had had a spontaneous vaginal delivery but there was an interval of 60 hours between rupture of the membranes and delivery. Pain had started in the left groin three days after delivery. At presentation all movements of the left hip were severely limited by pain, she was apyrexial. Investigations were as follows: Hb $7.9 \mathrm{~g} / \mathrm{dl}$, platelets $463 \times 10^{9} / 1$, WBC $9.8 \times 10^{9} / 1(60 \%$ neutrophils $)$, ESR $128 \mathrm{~mm} / \mathrm{h}$. Pelvic X-ray showed the left joint space to be reduced with some erosion of the superior acetabulum (see figure). The symphysis was also disrupted, presumably as a result of relaxation at the time of pregnancy followed by abnormal weight bearing.

The joint was aspirated under ultrasound control followed by arthrotomy and irrigation. A group B, $\beta$-haemolytic streptococcus which was penicillin sensitive was identified. Following surgical drainage and six weeks of antibiotics the patient's general health improved and the ESR returned to normal.

Group A streptococci (eg, Streptococcus pyogenes) were responsible for puerperal sepsis that was widespread during the middle of the last century. Now group B streptococci are recognised as important causes of neonatal and obstetric infections. ${ }^{2}$ Group B streptococci are common commensals of the vagina in postpartum women and in those who have experienced prolonged rupture of the membranes (greater than 12 hours) colonisation exceeds $80 \%{ }^{3}$ Following prolonged rupture of the membranes the incidence of neonatal infection and maternal morbidity (fever, urinary infection, endometritis) increase.

Septic infections of the $\mathrm{knee}^{5}$ and sacroiliac joints have also been described following pregnancy, the bacterial route of spread is likely to be haematogenous. The internal iliac veins are valveless and during episodes of raised intra-abdominal pressure, such as occurs in labour, blood is forced through the internal vertebral plexus of Batson. This route is via the lateral sacral veins and may explain the involvement of the sacroiliac joints in pregnancy. The vessels of the ligamentum teres drain into the obturator system and it is possible that the hip joint is also involved in this retrograde flow.

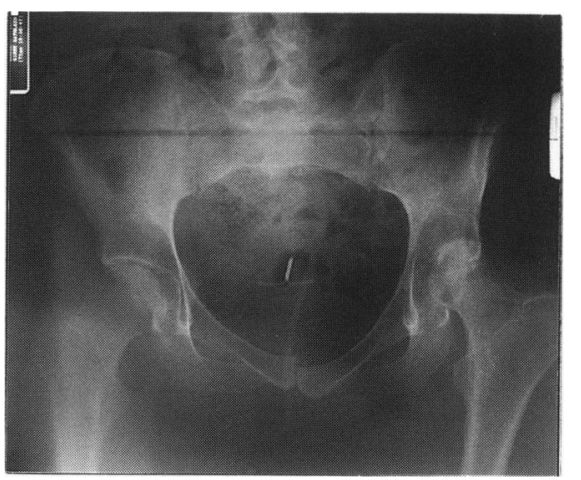

Figure Pelvic X-ray three months after the onset of symptoms 


\section{Summary points \\ - septic arthritis in an adult often has a predisposing factor \\ - group B streptococcal septic arthritis in a woman should raise the possibility of a genitourinary source}

Organisms isolated from septic joints in pregnancy include Pseudomonas aeruginosa Staphylococcus aureus, Mycoplasma hominis and our case of group B streptococcus.

JD HOWELL

RJ SHEDDON

Department of Orthopaedics, Mayday University Hospital, London Road, Croydon, Surrey CR7 7 YE, UK

1 Bulmer JH. Septic arthritis of the hip in adults. $\mathcal{F}$ Bone foint Surg 1966; 48-B: 289-98.

2 Reid TM. Emergence of group B Streptococci in obstetric and neonatal infections. BMF 1975; 2 : 533.

3 Gunn GC, Mishell DR, Morton DG. Premature rupture of the fetal membranes. Am $\mathcal{F}$ Obste Gynecol 1970; 160: 469-83.

4 Boyer KM, Gadzala CA, Kelly PD, Gotoff SP. Selective intrapartum chemoprophylaxis of neonatal group B Streptococcal early onset disease. $\mathcal{f}$ Infect Dis 1983; 148: 810-5.

5 Andrews BE. Mycoplasma hominis. Commun Dis Rep 1974; August.

\section{Causes of diarrhoea in patients with hypogammaglobulinaemia}

Sir,

Giardiasis is considered the commonest identifiable cause for diarrhoea in patients with hypogammaglobulinaemia. ${ }^{1,2}$ We recently reviewed the records of the patients with hypcgammaglobulinaemia and diarrhoea treated at our institution during the past 12 years and the results did not conform with this widely accepted notion.

Eight adult patients (six males, two females; ages ranging from 18 to 54 years) presenting with hypogammaglobulinaemia and diarrhoea were evaluated between 1982 and 1993 at the Gastroenterology Section of the Hospital das Clínicas de Ribeirão Preto (São Paulo, Brazil). The relevant data are summarised in the table.

Giardia lamblia was the unique pathogen detected in four patients. Although a sevenday course of metronidazole caused disappearance of $G$ lamblia from the stools and/or duodenal aspirate in all four, clinical response to treatment was seen in only two of them. Patient 8, a 54-year-old man, presented with a two-year history of chronic diarrhoea and a $20-\mathrm{kg}$ weight loss. Isospora belli cysts were found in a stool sample, but results of culture and parasitic studies for bacteria and other common pathogens, including $G$ lamblia, were negative. Relevant results of further investigations were: low serum immunoglobulin levels (IgG $310 \mathrm{mg} / \mathrm{dl}, \mathrm{IgA} 20 \mathrm{mg}$ $\mathrm{dl}$, and IgM $32 \mathrm{mg} / \mathrm{dl})$, high faecal fat (19 g/ $24 \mathrm{~h}$ ), and radiologic evidence of malabsorption. Oral trimethropim-sulfamethoxazole (140 $\mathrm{mg} /$ day), was started and resulted in resolution of diarrhoea within 48 hours, leading us to maintain the treatment for 30 days. Stool examination on days 7,8 , and 20 of therapy revealed cysts of $G$ lamblia but was negative for other pathogens. Taking into account the improvement of the patient and with his consent, $G$ lamblia tretment was not immediately given. On day 45 , when the patient had gained $13 \mathrm{~kg}$ and was asymptomatic, a seven-day course of metronidazole, $1.5 \mathrm{~g} /$ day, was given with no apparent effect.

$G$ lamblia was not detected in three patients; two of them had other pathogens detected in stool samples and had good clinical responses to treatment.

Although our findings are consistent with the notion that $G$ lamblia infestation is commonly associated with hypogammaglobulinaemia, ${ }^{3,4}$ they indicate that giardiasis may be innocuous for hypogammaglobulinaemic patients with diarrhoea, and the diarrhoea may be related to pathogens other than $G$ lamblia. As a corollary, the search for potential causes of diarrhoea in hypogammaglobulinaemic patients should not cease if $G$ lamblia is found in the stools. This notion is particularly important when evaluating patients living in poor sanitary conditions, thereby at an augmented risk of infection by several pathogens.

RICARDO BRANDT DE OLIVEIRA RUI FERNANDO BERTOLINO, JR Departamento de Clinicas Médica, Hospital das Clínicas de Ribeirão Preto 14048-900 Ribeirão Preto São Paulo, Brazil

1 Kagnoff MF. Immunology and inflammation of the gastrointestinal tract. In: Sleisenger $\mathrm{MH}$ Fordtran JS (eds). Gastrointestinal disease. 5th edn. Philadelphia; WB Saunders Company, 1993, pp 45-86.

2 Webster ADB. Giardiasis and immunodeficiency diseases. Trans $R$ Soc Trop Med Hyg $1980 ; 74.440-2$.

3 Ament ME, Ochs HD, Davis SD. Structure and function of the gastrointestinal tract in primary function of the gastrointestinal tract in primary immunodeficiency syndromes. A st

patients. Medicine 1973; 52: 227-48.

Hermans P, Diaz-Baxo J, Stobo J. Idiopathic late-onset immunoglobulin deficiency: clinical observations in 50 patients. $\mathcal{F} A M A$ 1975; 61: $221-7$

Table Summary of clinical data

\begin{tabular}{|c|c|c|c|c|}
\hline $\begin{array}{l}\text { Patient } \\
\text { no }\end{array}$ & $\begin{array}{l}\text { Characteristics } \\
\text { of the diarrhoea }\end{array}$ & $\begin{array}{l}\text { Identified } \\
\text { pathogen }\end{array}$ & Treatment & $\begin{array}{l}\text { Clinical response } \\
\text { to treatment }\end{array}$ \\
\hline 1 & intermittent, moderately severe & G lamblia & metronidazole & none \\
\hline 2 & steady, moderately severe & G lamblia & metronidazole & complete \\
\hline 3 & steady, watery, severe & $S$ stercoralis & cabendazole & complete \\
\hline 4 & steady, steatorrhea, severe & $\begin{array}{l}E \text { coli } \\
\text { (in jejunal aspirate) }\end{array}$ & $\begin{array}{l}\text { tetracycline } \\
\text { metronidazole }\end{array}$ & partial \\
\hline 5 & intermittent, mild & G lamblia & metronidazole & complete \\
\hline 6 & $\begin{array}{l}\text { steady, watery, } \\
\text { moderately severe }\end{array}$ & $\begin{array}{l}\text { Shighella flexneri } \\
\text { (in stools) }\end{array}$ & $\begin{array}{l}\text { trimethropim- } \\
\text { sulfamethoxazole }\end{array}$ & complete \\
\hline 7 & intermittent, mild & G lamblia & metronidazole & none \\
\hline 8 & steady, severe, steatorrhea & $\begin{array}{l}\text { Isospora belli } \\
+ \text { G lamblia }\end{array}$ & $\begin{array}{l}\text { trimethropim- } \\
\text { sulfamethoxazole }\end{array}$ & complete \\
\hline
\end{tabular}

\section{Polyorchidism: causation and management}

Sir,

Polyorchidism is a uncommon condition with only 90 cases having been reported in the accessible literature since $1670 .^{1-5}$ It is an anomaly which should be considered when assessing scrotal masses.

\section{Case report}

A 34-year-old man presented because of increased frequency and severity of the leftsided scrotal discomfort he had been having for many years. Two smooth swellings had been noted on the left side 20 years previously, one of which was thought to be an encysted hydrocoele of the cord. On this occasion two discrete smooth nontransilluminating masses were felt in the left scrotum and polyorchidism was diagnosed. At operation two small but normal looking testes were found on the left side (figure). The large upper and smaller lower testes shared a common epididymis. A single vas arose from the epididymis near the lower testis. Each testis had a separate blood supply. Biopsy of the testes showed normal spermatogenesis. The testes were fixed to each other and the tunica. At follow-up six months later the patient had had no further pain.

\section{Comment}

Embryologically, polyorchidism, or testicular duplication, is thought to result from transverse division of the urogenital ridge between the fourth and sixth week. The mesonephric tubules and duct are not involved, which explains the most common form of duplication in which there are two testes, a common epididymis and single vas, as in the case reported here. Complete duplication of testes, vasa and blood supply is extremely rare and is thought to be due to longitudinal division of the genital ridge and associated mesonephric tubules. ${ }^{1}$

Most patients present with a mass which may or may not be causing pain. Polyorchidism is rare but can be diagnosed clinically and differentiated from cysts, lipomata, and tumours. The diagnosis can be confirmed by ultrasonography. ${ }^{1-3}$ The commonest associated abnormalities are maldescent $(15-50 \%)$, which can affect either or both testes, and inguinal hernia $(30 \%) .^{5}$ Torsion has occurred in $15 \%$ of reported cases and

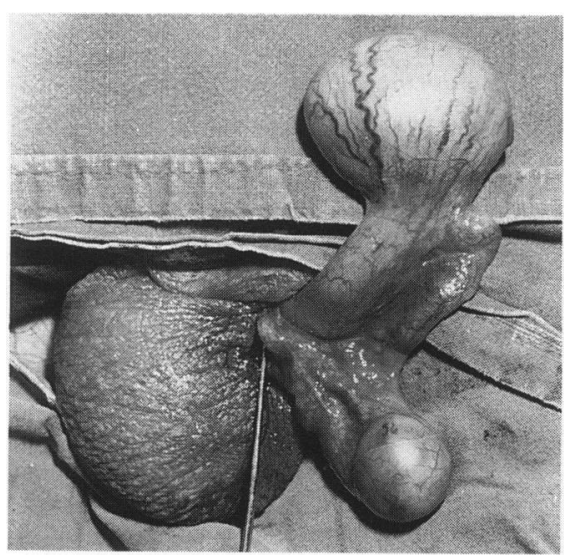

Figure Operative photograph showing the larger upper testis connected to the smaller lower testis by the common epididymis. The single vas is marked by the steel pointer 